\title{
As relações entre cristãos e muçulmanos na Índia do séc. XVI: os relatos de Zinadím e de Rodrigues da Silveira
}

Mariana Carolina Gois-Neves Universidade de Friburgo-Suíça

retende-se, com este trabalho, comparar duas obras que falam da presença portuguesa no Malabar, Índia, no séc. XVI, e que ilustram as tensões e relações entre cristãos e muçulmanos naquele litoral indiano. São elas Tuhfat al-mujahidin fi ba'd ahaul al Burtukaliyyin, ou "O Mimo do Campeão da Fé", do muçulmano Zinadím, e as Memórias de um Soldado da Índia, do português Francisco Rodrigues da Silveira. Ambas constituem uma fonte fundamental para o estudo do assunto em questão e exprimem dois pontos de vista que se opõem, que se atacam mutuamente mas que, ao mesmo tempo, coincidem em certos aspectos. No entanto, torna-se necessário precisar que a chegada dos portugueses ao Malabar constitui o tema principal do texto de Zinadím, enquanto que tal não se passa com o texto de Silveira. A questão muçulmana não é, por assim dizer, o fim último do seu livro, mas sim a crítica à administração colonial e à precaridade dos soldados na Índia. Passemos então ao estudo e comentário de ambas as obras. 


\section{Zinadím e Rodrigues da Silveira}

O livro de Zinadím, muito conhecido no Malabar entre os muçulmanos, ${ }^{1}$ aparece em Portugal em 1898, editado pela Imprensa Nacional. Existem dele quatro manuscritos, em Londres: um, que se encontra no British Museum; outro, pertencente à Asiatic Society; e dois outros que se encontram no India Office. Os manuscritos que servem de base à recolha de David Lopes, intitulada História dos Portugueses no Malabar, são o do British Museum, com o início do manuscrito da Asiatic Society. Porém, David Lopes acha que a totalidade da obra não pertence a Zinadim e que este é um comerciante de Calecut por demonstrar um conhecimento fino e detalhado de tudo o que diz respeito às comunidades muçulmanas estabelecidas na região do Malabar. ${ }^{2}$ Por outro lado, o livro é dedicado a Alí Aldixá, soberano de Bijapor que, bom conhecedor dos portugueses, teme o seu poder comercial e proselitismo cristão. Mas Zinadím não faz qualquer alusão ao assassinato do monarca, em 1579, o que significa que o livro é posterior a essa data e a sua autoria é de outra pessoa. ${ }^{3}$ Duncan, no tomo V dos seus Asiatic Researches crê, pelo contrário, que Zinadím é um árabe, egípcio ou um vassalo dos turcos enviado para a Índia para fazer frente aos portugueses.

\footnotetext{
1 "É bastante vulgar no Malabar entre as famílias muçulmanas do país". ZINADIM, 1998, p. 11.

2 " [...] inclinamo-nos a crer que fosse natural do Malabar e ali vivesse, provavelmente em Calecute. A minúcia com que fala dos acontecimentos aí passados, e das comunidades muçulmanas estabelecidas na costa, é o que no-lo parece indicar." LOPES, 1998, p. 12.

3 "Não parece ser toda do mesmo autor. Sendo dedicada a Alí Adilxá, que foi assassinado em 1579, a parte posterior a este ano deve ter sido acrescentada por outrem, porque se fosse o mesmo não deixaria sem dúvida de se referir a esse facto." LOPES, 1998, p. 12.
} 
Quanto às Memórias de um Soldado da Índia, trata-se da obra menos conhecida entre todas as que falam da Índia, mas a sua pobreza literária é compensada pela utilidade das informações históricas. O manuscrito, encontrado na biblioteca do British Museum, divide-se em duas partes com assunto totalmente diferente embora o tema da justiça seja comum. A primeira parte - Reforma das milícias e do governo do estado da Índia Oriental - fala da experiência pessoal de R. da Silveira como 'soldado prático' do exército português no Oriente, entre 1585 e 1597, enquanto que a segunda - Discurso sobre a reforma da justiça na comarca da Beira e Entre-Douro-e-Minho - narra um problema judicial após o seu regresso à metrópole.

No entanto, é necessário precisar em que consiste um 'soldado prático' para melhor se compreender a obra de Silveira. Trata-se de um soldado de patente inferior, de condição humilde, frequentemente com uma preparação precária e recrutamento forçado. Encarregado de vigiar as fortalezas e navios da Índia em nome da coroa, a sua preparação insuficiente é compensada por uma longa estadia no Oriente e pelo conhecimento pragmático e empírico da realidade militar e administrativa local. É por isso que o soldado Silveira resolve narrar o produto das suas observações directas, propondo, simultaneamente, reformas na gestão e administração coloniais.

Uma questão se levanta, contudo: será Rodrigues da Silveira o verdadeiro autor das Memórias? Como explicar as digressões e alusões culturais num soldado prático, a priori um simples militar desprovido de instrução? A resposta resta em aberto...

\subsection{O Mimo do Campeão da Fé, de Zinadím}

O princípio do livro dá-nos informações de carácter religioso e o ponto de vista do autor a esse respeito. Esses aspectos são pertinentes, pois ajudam a compreender o raciocínio de Zinadím e a sua interpretação dos factos narrados. 
Zinadím afirma haver duas categorias de fiéis: os que habitam o próprio país e os que invadem os territórios muçulmanos, "como é o caso do Malabar". ${ }^{4}$ Quanto aos primeiros, basta que os autóctones lhes façam guerra santa, na qual os restantes muçulmanos não são obrigados a participar, a não ser que sejam pecadores. Neste último caso, a sua participação é obrigatória. Quanto aos segundos, a guerra "é imperativa", ${ }^{5}$ todos os crentes devem participar solidaria e unanimemente pois receberão "a recompensa dos anjos, dos profetas e enviados" ${ }^{6}{ }^{6}$

Antes de falar do Malabar, Zinadím menciona, porém, alguns preceitos de natureza militar e, de um modo reiterativo e repetitivo, como os pensadores muçulmanos, cita o Corão. Enumera também um conjunto de citações da autoria de figuras prestigiadas da história do Islão, que, muitas vezes, também citam as palavras do Profeta. ${ }^{7} \mathrm{O}$ propósito de Zinadím é, sem dúvida, legitimar os seus pontos de vista, analisar os acontecimentos históricos à luz da sua fé. Nessa perspectiva, ele aconselha os combatentes a rezar, a suplicar a Deus e a temê-

${ }^{4}$ ZINADÍM, 1998, p. 25.

5 "que seja escravo, mulher, citadino ou camponês, mesmo sem autorização do seu senhor, esposo, credor ou proprietário da terra; quer para os que estão perto deles [dos infiéis], quer para os que estão deles afastados". ZINADIM, 1998, p. 25.

${ }^{6}$ ZINADÍM, 1998, p. 27.

${ }^{7}$ Há cerca de trinta citações de pensadores muçulmanos prestigiosos, tais como Moceleme, Annaçaí, Jaber Samara, Masruque, Abú Muça, Abú Saíde, Abú Queiz, Abú Abaz, Abú Horeira, Abú Daúde, Attirmedí, Harame ben Fatique, Sahle Ben Sahde, Abdalá Benomar Benalace, Amram Ben Huçáim. Cito um exemplo: "Sahle Ben Sahde diz: o Profeta diz: a vida de um dia no combate pelo amor de deus vale mais do que o mundo e os seus prazeres" (LOPES, 1998, p. 31). 
Lo, a esquecer todo o tipo de ameaça e abster-se de praticar qualquer fraude relativa aos espólios de guerra. É apenas na última parte do livro que o autor se refere à chegada dos portugueses ao Malabar, após ter falado das origens da presença muçulmana nas costas indianas. "Todos os muçulmanos [afirma ele] são súbditos de povos infiéis", mas combatem contra "todos os inimigos da fé, ajudados pelo samorim, amigo dos muçulmanos. ${ }^{8}$

Chegados à Índia em 1498, o objectivo dos portugueses, pejorativamente chamados de franges, é a posse do monopólio do comércio da pimenta, sem a intervenção de qualquer intermediário. " "São as especiarias o principal motivo da longa travessia desde o seu país até à Índia". ${ }^{10}$ Com esta intenção, os portugueses estabeleceram-se então nos dois principais portos do país, Cochim e Cananor, e conquistaram Goa, a futura sede do seu governo no Oriente. Para responder aos seus fins comerciais, constroem fortalezas em lugares estratégicos e adoptam medidas hostis contra os seus principais concorrentes, os muçulmanos: destruição de mesquitas e posterior construção de igrejas, a obrigação imposta aos navios muçulmanos de ostentar a bandeira portuguesa e limitar o comércio do harenque, vestuário e noz de coco.

Os franges mostraram-se desde logo hostis para com os muçulmanos [comenta Zinadím] nas transacções comerciais [...] as mercadorias, das quais eles obtinham enormes lucros e sobre as quais eles adquiriram o monopólio, mediante exclusão dos mercadores muçulmanos, são: a

${ }^{8}$ ZINADÍM, 1998, p. 26.

9 "grandes armadas chegavam de Portugal todos os anos sem interrupção e regressavam a Portugal provenientes do Malabar com pimenta, gengibre e outras especiarias". ZINADÍM, 1998, p. 57.

${ }^{10}$ ZINADÍM, 1998, p. 55. 
pimenta, o gengibre, a canela, o cravo, o funcho e outros produtos de grande utilidade, não deixando aos muçulmanos senão o comércio do harengue, da noz de coco, do vestuário e produtos análogos. ${ }^{11}$

Zinadím sublinha o poder comercial dos portugueses, ${ }^{12}$ mas não esconde o ódio e o ressentimento que nutre por eles. Acrescenta ainda que esses comercializam as mercadorias provenientes de lugares longínquos, exportando-as para países igualmente longuínquos, motivo pelo qual eles se tornaram tão poderosos que, por um lado, os governadores dos portos não reconhecem senão a sua jurisdição; por outro, as viagens marítimas dependem da sua autorização. "Numerosas cidades são conquistadas graças ao seu tacto e saber"13 (Ormuz, Maldivas, Samatra, Malaca, Molucas, Meliapor, os portos de Ceilão e mesmo da China). Sem nunca desobedecer aos superiores, "nunca se ouviu falar que um dos seus capitães tivesse sido assassinado por cobiça de poder", 14 pelo que existe uma certa união que se opõe à divisão e falsidade dos muçulmanos, aliás, inerente aos próprios soberanos. A desorganização, a ambição de poder, a rivalidade entre os soldados e capitães muçulmanos são as principais causas das suas derrotas militares e da precariedade económica do povo.

Porém, a origem desta instabilidade remonta ao período da instalação dos portugueses no Malabar, no momento em que alguns reis, nomeadamente o de Cochim, colocaram os seus sobrinhos no trono ajudados pelos portugueses, em troca

11 ZINADÍM, 1998, p. 54 e 91-92.

12 “Depois, eles edificaram [em Goa] um grande número de fortalezas; o seu poder aumentou de ano para ano, de mês para mês, porque Deus Todo-Poderoso assim o quis". ZINADÍM, 1998, p. 62.

13 ZINADÍM, 1998, p. 90.

${ }^{14}$ ZINADÍM, 1998, p. 66. 
de favores, honras, apoio militar e outros privilégios. Como resposta a essas usurpações, o samorim de Calecute declarou guerra a esses soberanos, tendo cometido vários assassinatos. Instalou-se então o caos e a divisão em detrimento da antiga prosperidade e convivialidade que reinava entre os muçulmanos, como resposta aos pecados e revoltas que eles cometeram contra Deus.

No entanto, o autor não tece detalhes sobre o que realmente se passou porque se limita a dizer que houve uma punição divina, que o Senhor lhes enviou os franges para os tiranizar e castigá-los. Pelo contrário, afirma que o seu povo, instalado no Malabar desde o séc. IX, não soube agradecer a afabilidade e hospitalidade dos príncipes hindús, desrespeitou-os, pelo que sofreu disso as consequências:

os muçulmanos do Malabar viviam no bem-estar e comodidade graças à gentileza dos príncipes do país, ao respeito pelos antigos costumes e à doçura da sua convivialidade. Eles [os muçulmanos], esqueceram contudo estes benefícios; pecaram, revoltaram-se contra Deus, que lhes enviou como senhores os franges - que Deus queira abandoná-los! - que os tiranizaram, corromperam, e praticaram actos ignóbeis e infâmes. ${ }^{15}$

Zinadím enumera um conjunto de vexações contra os seus:

[...] eram inumeráveis as violências, o desprezo, a derisão quando os Portugueses os obrigavam a trabalhar; traziam os seus barcos para terra, deitavam-lhes lama na cara e no corpo, cuspiam-lhes em cima, tiravam-lhes as mercadorias, proibiam-lhes as peregrinações, roubavam-nos, incendiavamlhes as cidades e mesquitas, profanavam os lugares sagrados das mesquitas, confiscavam os navios, maltratavam

${ }^{15}$ ZINADÍM, 1998, p. 62-63. 
o Livro Santo e os seus adeptos, pisando-O e incendiando$\mathrm{O}$; incitavam os muçulmanos à apostasia e adoração da cruz, ornavam as suas mulheres com jóias e ricos vestidos tirados às mulheres dos muçulmanos, assassinavam os peregrinos e outros muçulmanos com todo o tipo de violências, insultavam publicamente o Apóstolo de Deus, prendiam os muçulmanos, acorrentavam-nos, arrastavamnos até às praças públicas e vendiam-nos como escravos ou tentavam elevados resgates; metiam-nos em locais escuros, infectos e sinistros, dando-lhes pontapés quando faziam abluções; torturavam-nos com fogo, vendiam uns, escravizavam outros; com outros, praticavam actos cruéis, reveladores de falta de sentimentos humanos [...] esta inimizade manifesta-se unicamente contra os muçulmanos e sua fé, não contra os naires ou indivíduo de outra religião. ${ }^{16}$

Outra humilhação, a cristianização forçada dos muçulmanos, muitas vezes sob ameaça de expulsão, como o ilustra o episódio ocorrido em Goa, em 1562, no qual muitos tiveram de abandonar a cidade. Porém, comenta Zinadím, estas atitudes não vêm dos capitães portugueses, mas sim de indivíduos de nível inferior que influenciam os chefes à conversão forçada dos muçulmanos. "O seu grande desejo e preocupação, quer entre os mais velhos, quer entre os mais jovens, é arrancá-los à fé muçulmana, obrigálos a entrar na Igreja cristã", afirma Zinadím, ${ }^{17}$ que menciona ainda as querelas com os judeus, aliados dos portugueses e as guerras desses dois povos contra os muçulmanos, apoiados pelo samorim, em Cranganor, em 1524. Muitos foram mortos, muitas igrejas e sinagogas incendiadas mas, no ano seguinte, deu-se a vingança, com a destruição de casas, lugares santos, lojas, abate de coqueiros nas margens dos rios, tortura e

\footnotetext{
${ }^{16}$ ZINADÍM, 1998, p. 63-65.

17 ZINADÍM, 1998, p. 64.
} 
assassinato de grande número de muçulmanos, em Panane e Pandarane.

Este acidente assinala, para Zinadím, o início do ódio dos portugueses contra os muçulmanos e contra o samorim. Esse ódio, que não cessou de aumentar com o decurso dos anos, desplotou uma série de confrontos sucessivos que culminaram com a fragilização e empobrecimento do samorim e seus aliados: "os súbditos e seus aliados continuaram a guerra por muitos anos e, assim, eles cansaram-se e empobreceram" ${ }^{18}$

Se Zinadím apela aos desígnios divinos, ele não deixa, contudo, de apostrofar pejorativamente aos portugueses, desejando-lhes, por exemplo, "que Deus combata contra eles, que os maldiga, que os abandone, que Deus, glorioso e omnipotente, os castigue" ${ }^{\prime 19}$ Ao mesmo tempo, ele insiste na idéia de que o seu povo pertence a Deus e a Deus regressará, citando uma frase do Corão: "Sem dúvida que nós pertencemos a Deus e a Ele regressaremos". ${ }^{20}$

Estas imprecações são simultaneamente um meio de exorcizar o rancor e um apelo a Deus contra os inimigos do seu povo. A última sentença é uma espécie de sinal de esperança: o castigo não é eterno, a felicidade restabelecer-se-á um dia entre as criaturas de Deus, num momento oportuno, porque o bem sucede ao mal e a perserverança é recompensada: "Nós esperamos que Deus nos dê um próximo consolo e uma boa perserverança porque Ele diz: Deus dará o bem depois do sofrimento porque o bem sucede ao sofrimento e o sofrimento sucede ao bem". ${ }^{21}$

\footnotetext{
18 ZINADÍM, 1998, p. 71.

19 ZINADÍM, 1998, p. 59, 62, 64, 83.

20 ZINADÍM, 1998, p. 75 (Corão, II, 151).

${ }^{21}$ ZINADÍM, 1998, p. 103.
} 


\subsection{As Memórias de um Soldado da Índia, de Francisco Rodrigues da Silveira}

Silveira chama Relação à sua obra, afirmando que se trata de algo simples, de uma espécie de relatório pragmático, que se limita à mera exposição de factos precisos, da verdade, em detrimento da elegância do estilo:

E porque a descrição das terras em particular e dos confins de cada uma, como e de onde provém cada nação é sobretudo assunto da história e não de uma simples Relação de coisas particulares e limitadas: livro sem pretensões empírico, simples, com acontecimentos precisos, restrito ao necessário, ao útil [...] quando me faltar esta elegância e delicadeza exigidas em tais textos, não me faltará a verdade que, neste assunto, deve ser estimada como o maior e mais excelente estilo a empregar. ${ }^{22}$

Nas palavras de Rodrigues da Silveira, o seu principal objectivo é denunciar os vícios, a corrupção e a desordem militar e administrativa que reinam no Estado português da Índia, a fim de curar estas doenças e evitar a condenação das almas pecadoras. Como "boa testemunha de vista", ${ }^{23}$ Silveira coloca-se ao serviço de Deus, da pátria e do rei, consciente de que ele será recompensado no Além: "quanto a mim, aceitarei tranquilamente tudo o que me acontecer ao serviço de Deus, do rei e da pátria porque tenho a certeza de que, enquanto neste mundo, o zelo não tem recompensa no outro, no qual cada um é recompensado pelo seu trabalho, o prémio merecido não me será negado" ${ }^{24}$

$\mathrm{O}$ autor acrescenta então que as causas da presença portuguesa no Malabar são exclusivamente económicas; que o

${ }^{22}$ RODRIGUES DA SILVEIRA, 1987, p. 64.

${ }^{23}$ RODRIGUES DA SILVEIRA, 1987, p. 63.

${ }^{24}$ RODRIGUES DA SILVEIRA, 1987, p. 150. 
objectivo é a posse do comércio das especiarias e das drogas, outrora na posse dos venezianos, o desvio da rota comercial do Mediterrâneo para o Atlântico, e posterior redistribuição dos produtos indianos pela Europa. Enfim, a intenção principal dos portugueses não é dominar a terra, conquistá-la, mas sim fazer comércio e utilizar o mar como comerciantes.

No entanto, na opinião de Silveira, deverá haver uma ocupação territorial acompanhada do processo de evangelização e de construção de igrejas. Neste sentido, a cristianização justifica o combate e a conquista efectiva porque o proselitismo religioso é, a seu ver, mais importante do que o tráfico comercial. Deste modo, para o autor, a concorrência comercial é a principal fonte de conflitos e ela é valorizada pelos portugueses em detrimento da fé. Tal significa portanto que, para combater as nações da Índia impõe-se a arma do Cristianismo, a única apta a destruir as outras religiões da Índia, apanágios do diabo:

Quantas guerras não foram feitas na Índia, descoberta unicamente para abrir e defender o caminho do comércio e das mercadorias, contra o que se devia esperar de uma nação que se diz muito católica e combatente? Querem que as nações da Índia se convirtam à fé católica? Combatamnas com as armas contrárias àquelas com as quais o diabo as subjugou. ${ }^{25}$

Por esta ordem de idéias, é interessante referir o retrato que Silveira faz do indiano e do muçulmano. O primeiro é ágil, ligeiro, desenvolto, mais medroso, despreocupado e isento de raciocínio. Quanto ao muçulmano, ele era outrora próspero no comércio, actividade que os naturais abandonaram, mas a chegada dos portugueses empobreceu-os. Alguns venderam os bens, procuraram outras profissões ou instalaram-se em Meca; outros tornaram-se corsários ou piratas. Trata-se de "gente vil

${ }^{25}$ RODRIGUES DA SILVEIRA, 1987, p. 181. 
e apoucada", ${ }^{26}$ que urge aniquilar a todo o custo. Apesar da precariedade e insuficiência das tácticas militares dos portugueses, as vitórias destes devem-se ao medo, à moleza dos indianos e à desordem e aparato presunçoso da marinha muçulmana, não, de modo algum, à eficácia do a parelho militar e administrativo lusitano.

Quando Silveira alude à miséria do 'soldado prático', ele faz paralelamente um retrato dos portugueses chegados à Índia: frequentemente expulsos de casa, eles vêem-se obrigados a embarcar em navios de guerra, sob pena de prisão. Muitos, 'empobrecidos, miseráveis, esfomeados, ${ }^{27}$ até tratados como escravos, fogem para portos de salvamento como Bengala, Birmânia, China ou Malaca, locais onde se colocam ao serviço de chefes hindús ou muçulmanos. Caso contrário, tornam-se ociosos ou malfeitores, dedicando-se ao jogo, à coscuvilhice, ao roubo, ao crime, ao adultério ou à mendicidade nos átrios dos conventos. E Silveira acrescenta: "É por isso que a soldadesca portuguesa é composta por alguns ex-condenados, miseráveis a mendigar nos portais dos conventos e, a maior parte, por celerados que mereciam mais o nome de malfeitores do que de soldados" ${ }^{28}$ A culpa, a seu ver, é da administração portuguesa, embora o clima e o carácter dos compatriotas, propício à emulação, sejam factores negativos. O primeiro factor torna-os efeminados, receptivos à luxúria e à moleza; o segundo factor faz com que eles imitem os costumes e estilo de vida dos autóctones, um comportamento prejudicial à sua reputação. ${ }^{29}$

${ }^{26}$ RODRIGUES DA SILVEIRA, 1987, p. 67.

${ }^{27}$ RODRIGUES DA SILVEIRA, 1987, p. 194.

${ }^{28}$ RODRIGUES DA SILVEIRA, 1987, p. 186.

29 "...neles, é coisa muito comum abraçar facilmente os costumes, roupas e cerimónias das outras nações, com tanta ligeireza e inconstância que isto diminui grande parte da sua reputação". RODRIGUES DA SILVEIRA, 1987, p. 183. 


\section{Zinadím e Silveira: semelhanças e dissemelhanças}

Muitos factos narrados por Zinadím coincidem com os de Silveira que vê, também ele, os portugueses como intrusos, usurpadores e odiados pelos locais, não só devido à dependência comercial com que colocaram os muçulmanos, como também devido à violência, tirania e vexações exercidas no território: "Neste sentido, nenhuma prova é necessária: tendo em conta as vexações e tiranias, daí resulta claramente o ódio e desejo de vingança, causa de guerras e cerco de cidades e fortalezas, que tanto custaram, como toda a gente sabe ${ }^{\prime \prime 30}$ - afirma Silveira. Como exemplo, o autor cita a iniciativa do grão-mogol do Hindostão: o poderoso imperador comprou navios em Constantinopla e recrutou aí especialistas em construção naval a fim de combater os portugueses e expulsá-los do país.

Mas Silveira comenta ainda que, entre os seus compatriotas, ninguém obedece a ninguém na guerra, que "cada um é capitão e sargento de si-próprio", ${ }^{31}$ enquanto Zinadím reconhece que a intuição, o saber do inimigo e a obediência cega aos superiores são a causa do sucesso militar dos portugueses: "Eles, graças ao seu tacto e saber, apoderaram-se de muitas cidades" Isso significa que, apesar da desorganização, a victória joga em favor dos portugueses e este facto é reconhecido pelos locais.

A este propósito, Zinadím refere ainda uma questão fundamental que explica, em grande parte, a degradação crescente da comunidade muçulmanna do Malabar: a superioridade militar portuguesa, o medo da violência e represálias por parte dos autóctones não justificam exclusivamente o sucesso português no Malabar. Este deve-se também ao facto

${ }^{30}$ RODRIGUES DA SILVEIRA, 1987, p. 163.

${ }^{31}$ RODRIGUES DA SILVEIRA, 1987, p. 41.

32 RODRIGUES DA SILVEIRA, 1987, p. 90. 
de os portugueses terem compreendido os jogos políticos e institucionais intestinos, as rivalidades dinásticas e disso se terem aproveitado para alargar o seu domínio. No fim de contas, os portugueses aproveitaram a desunião reinante, a traição dos ministros dos príncipes para reforçar a sua presença comercial. $\mathrm{O}$ 'tacto' de que fala Zinadím é seguramente esta estratégia oportuna que os portugueses conseguiram edificar com vista à concretização dos seus objectivos. Eis alguns exemplos disso: "o samorim enviou embaixadas aos soberanos muçulmanos para obtenção de apoio, mas só o rei de Guzarate [...] mandou preparar navios que, contudo, nunca desembarcaram". ${ }^{33}$ Entre 1534 e 1536, alguns ministros dos reis Aldixá de Guzerate e Nizamxá de Deli conspiram contra eles e, com o apoio dos portugueses, conseguem fazer um outro monarca subir ao trono de Goa. Um ano mais tarde, em 1537, desencadeia a guerra entre Solimão Paxá, ministro do imperador do Egipto, e o emir de Aden. O samorim de Calicute, receando a violência, autoriza os portugueses a construirem fortalezas na região exigindo, como contrapartida, a autorização para o envio de navios muçulmanos para os portos de Aden, da Arábia e de Judá, sempre com as insígnias portuguesas. No entanto, esta permissão é anulada mais tarde e a "opressão dos franges recomeçou, assim como os males contra os muçulmanos e outros povos". ${ }^{34}$

No que diz respeito à Relação de Silveira, ela parece ser um testemunho verídico da realidade portuguesa na Índia, mas ela é também o produto de um homem cheio de rancores e ressentimentos, que se compraz em 'exagerar' a verdade para, por um lado, exorcizar a sua revolta e, por outro, inspirar indignação no leitor face aos acontecimetnos narrados. Isso quer dizer que as Memórias não são tão neutras e objectivas

33 ZINADÍM, 1998, p. 58.
${ }^{34}$ ZINADÍM, 1998, p. 67. 
como o afirma o autor e este aspecto não passa despercebido ao leitor atento. $O$ facto de Silveira se considerar digno de recompensa divina pelos serviços rendidos ao seu país numa Índia viciada e corrupta revela um indivíduo que se crê uma vítima, um mártir. Em suma, ele exagera, insiste nas suas opiniões, o que o torna parcial nas suas afirmações. Podemos igualmente constatar que a sua ideologia e proselitismo religiosos, que a sua defesa de uma colonização 'terrestre' (de improvável execução, além do mais) são produto de uma mentalidade tradicionalista. O pragmatismo de Silveira provém, de certeza, da sua experiência directa como 'soldado prático', não de uma longa e sólida formação cultural ou livresca.

Se Silveira proclama a cristianização dos indianos em detrimento do comércio, Zinadím propõe, como vimos, a guerra santa, a união de todos os muçulmanos contra o intruso europeu; esta cruzada é tanto mais legítima quanto o frange é um infiel de segunda categoria porque ele invadiu os territórios muçulmanos. Por conseguinte, Zinadím e Silveira partilham a mesma atitude hostil em relação ao 'outro': a incompreensão e intolerância são recíprocas e ambos os autores são um bom exemplo disso.

Compreendemos igualmente a razão de ser dos primeiros capítulos do livro de Zinadím, o qual se inspira na fé para manter viva a esperança de dias melhores para os muçulmanos do Malabar. Por isso ele apela à perseverança e à luta permanente contra o usurpador, por isso ele cita frases do Corão, tecendo, ao mesmo tempo, comentários de natureza escatológica. $\mathrm{O}$ sofrimento do seu povo terá uma recompensa de Deus, tal como Silveira, denunciador da corrupção e vícios.

A ideologia religiosa de Zinadím explica a problemática das relações entre portugueses e muçulmanos dado que é uma decisão divina que fundamenta a infelicidade destes, causada pela chegada inesperada dos primeiros. Aliás, Zinadím repete 
muitas vezes que "foi Deus Todo Poderoso que assim o quis",, 35 "que assim o determinou Deus, Todo Poderoso e Omnisciente, cujos decretos são inevitáveis e a Sua vontade invencível". ${ }^{36}$ Como decisão divina, ela é portanto irreversível, sendo incondicionalmente necessário respeitá-la. Zinadím vai ainda mais longe ao sugerir que a hostilidade dos portugueses se manifesta unicamente contra os muçulmanos, não contra as outras comunidades; que ela é, por assim dizer, de origem comercial e também religiosa. ${ }^{37}$ Tal como Silveira, Zinadím é um homem rancoroso e os seus sentimentos transparecem nas suas contradições e no tom das suas afirmações. Ora, o Malabar não é um país muçulmano. Por que fazer então a guerra santa, tanto mais que os muçulmanos representam aí uma minoria, como o próprio autor o afirma: "os muçulmanos são seus súbditos e, pouco numerosos, porque não atingem, sequer, um décimo da população" ${ }^{38}$

Quanto aos judeus, eles aliam-se muito provavelmente aos portugueses contra os muçulmanos por motivos religiosos e comerciais, e a persistência daqueles faz com que a comunidade muçulmana seja relegada para segundo plano. De facto, os acontecimentos posteriores assim o confirmam: sucedem-se uma série de tragédias e conflitos, em 1531, 1534, 1571, 1577, todos eles assinalados pela vitória indiscriminada, ou dos portugueses ou dos muçulmanos. Temos, como exemplo, o cerco de Chalé, em 1571. Esfomeados, os "portugueses [...] comeram cães e outras coisas imundas e atiram um grande número de escravos ou convertidos das fortalezas por falta de víveres". ${ }^{39}$ E estes

\footnotetext{
35 ZINADÍM, 1998, p. 67.

${ }^{36}$ ZINADÍM, 1998, p. 82.

37 ZINADÍM, 1998, p. 65.

38 ZINADÍM, 1998, p. 50.

39 ZINADÍM, 1998, p. 100-101.
} 
conflitos manifestam-se de várias maneiras, tais como captura de navios ou reféns, destruição de fortalezas, incêndios de casas ou lojas, torturas, flagelações, cerco de cidades ou fortalezas, etc. Trata-se de uma sucessão repetitiva de guerras, de violências e represálias que levam à resignação da população local, dos seus príncipes e à aceitação dos portugueses no território.

Finalmente, em 1586, há um tratado de paz e de amizade entre o samorim e o vice-rei português, D. João de Mascarenhas. Oitenta-e-oito anos de dissensões e de crueldades...

\section{Conclusão}

Se nos basearmos no relato de Zinadím, sem emissão de juízos de valor quanto à sua veracidade, constatamos que a sua raiva e hostilidade face aos portugueses são, em parte, justificáveis. A meu ver, é necessário encontrá-las no passado histórico.

Com efeito, a presença árabe-muçulmana no subcontinente indiano é muito antiga e a sua contribuição cultural e econômica ao país é considerável. Já antes da conversão dos árabes ao Islão, mercadores da Península Arábica percorrem o Mar Vermelho e comercializam especiarias no Malabar. Eles detêm vários centros de comércio ao longo desta região costeira da Índia ocidental, com a autorização das autoridades locais, e transportam os seus produtos desde o lémen até aos portos da Síria, a fim de serem depois distribuídos na Europa pelos venezianos. Este tráfico próspero acompanha a intensificação da presença muçulmana na Índia depois da conquista de uma parte do Paquistão actual, em 712, pelos Omíadas, e pelo estabelecimento, no Malabar, de alguns muçulmanos opositores a esta dinastia.

O processo não cessa de se intensificar nos anos seguintes, sobretudo no séc. XIII, quando as dinastias turcas conseguem implantar reinos regionais islamizados no subcontinente. É o 
caso da dinastia dos Ghazni, conquistadores da Pérsia, da qual Dibak se torna o primeiro rei muçulmano na Índia; da dinastia dos Khalji, inimigos dos mongóis; da dinastia dos Tughlas, dos Sayydes ou dos Lodi, estas duas últimas reinantes em Nova Deli. Estes reinos favorecem o desenvolvimento das artes, assim como a expansão do Islão e o sincretismo religioso. Muitos persas refugiam-se na Índia, devido às invasões mongóis, e este facto contribui para a consolidação da presença muçulmana no país. A coexistência entre os dois povos, o hindú e o muçulmano, é pacífica, sobretudo no sul, zona mais protegida contra eventuais ataques vindos do exterior. Ambas as comunidades se aceitam reciprocamente e têm lugar trocas culturais a nível religioso, musical, artístico e mesmo científico.

Muitos muçulmanos vivem então no Malabar, onde eles detêm o monopólio do comércio desde o séc. XIII. Aliás, são estes muçulmanos do Malabar que iniciam, na altura, graças ao tráfico das especiarias, um movimento de expansão em direcção à Malásia e à Indonésia, regiões que abandonarão mais tarde o Budismo e o Bramanismo a favor do Islão. ${ }^{40}$

Ora, a chegada dos Europeus vem fragilizar esta estrutura ancestral, este sistema de equilíbrio árabe-indiano, sobretudo a partir de 1506, momento em que os portugueses edificam as primeiras fortalezas no oeste indiano, em Cochim, Quíloa e Cangranor. Paralelamente, eles apoderam-se do comércio das especiarias e impõem o tributo sobre a navegação comercial às populações muçulmanas do mar de Omã. Algumas cidades, como Goa, Damão e Diu, ser-lhes-ão posteriormente cedidas, apesar da aliança (sem sucesso) entre o sultão do Egipto, o samorim de Calecute e o rei de Guzarat, nos princípios do séc. XVI.

40 "The most important Arab settlements were in Malabar where Muslins now form a substancial part of the population and where a local ruler adopted Islam in the early part of the ninth century". Cf. SYED, 2003, p. 21. 
O sucesso português deve-se, sem dúvida, às divisões internas no seio das autoridades indígenas, à superioridade militar ocidental e à determinação feroz dos portugueses em levar a cabo os seus fins comerciais. Não é um acaso se, em 1494, aquando da assinatura do tratado de Tordesilhas, o rei português D. João II reivindica a metade oriental do globo terrestre, projecto que lhe vai permitir contornar a África e chegar à Índia por via marítima. Aliás, o 'soldado prático' Diogo do Couto confirma os interesses económicos dos seus compatriotas no seu livro O Primeiro Soldado Prático. A pimenta, afirma ele, é uma especiaria sem a qual Portugal não pode passar: "Portugal é como a ostra: não a podemos comer sem pimenta" ${ }^{41}$ Couto alude também aos venezianos e aos muçulmanos como exconcorrentes dos portugueses e seus actuais inimigos.

Podemos assim dizer que a raiz das hostilidades entre portugueses e muçulmanos na Índia são, no início, de natureza comercial. ${ }^{42}$ Com efeito, o objectivo dos portugueses é bem preciso: a obtenção do monopólio das especiarias, uma actividade da qual a comunidade muçulmana detinha a primazia desde a sua instalação no Malabar, por volta do séc. IX. Esta usurpação assinala o declínio dos mercadores muçulmanos e favorece os conflitos dinásticos e as rivalidades internas subjacentes entre hindús (os naires), judeus e muçulmanos. Em resumo, neste contexto da Índia do séc. XVI, as disputas religiosas acentuam as rivalidades económicas, servem de pretexto à obtenção da hegemonia comercial e política.

${ }^{41}$ COUTO, 2001, p. 503.

42 "The object of the Portuguese was twofold- to regain direct access to spices and other goods of the Indies for which Western Europe was now dependent on Egypt and Venice, and to wrest the trade and political power in the east from the Arabs." Cf. SYED, 2003, p. 131. 


\section{Referências}

ALBUQUERQUE, Luis. de. Os Descobrimentos Portugueses. Lisboa: Alpha, 1986.

ALBUQUERQUE, Luis. de. Crónica do Descobrimento e Primeiras Conquistas da Índia pelos Portugueses.Introdução, leitura, actualização, notas e glossário de Luís de Albuquerque. Lisboa: Imprensa Nacional-Casa da Moeda, [s.d.].

COUTO, Diogo do. O Primeiro Soldado Prático. Introdução e edição por António Coimbra Martins. Lisboa: Comissão Nacional para as Comemorações dos Descobrimentos Portugueses, [s.e.], 2001.

OLIVEIRA MARQUES, Antônio Henrique de. Breve História de Portugal. Lisboa: Presença, 2003.

RODRIGUES DA SILVEIRA, Francisco. Memórias de um Soldado da Índia; compiladas de um manuscrito português do Museu Britânico por A. de S. S. Costa Lobo. Lisboa: Imprensa Nacional, 1987.

SYED, M. H. History of Muslims in India. Edited by M. H. Syed. New Delhi: Anmol Publications PVT.LTD, 2003.

ZINADÍM, M. História dos Portugueses no Malabar. Lisboa: Antígona, 1998. 


\section{Resumo}

Muitas questões se levantam sobre a chegada de Vasco da Gama à Índia, em 1498: as intenções dos Portugueses, neste território, serão verdadeiramente comerciais? Como reagem as comunidades locais, nomeadamente os hindús, judeus e muçulmanos à chegada inesperada dos Europeus? Esta chegada vai ou não provocar um desequilíbrio de forças entre estes grupos? Em que domínio? Religioso, político, económico, ou todos eles? Como são as relações entre cristãos e muçulmanos na Índia antes da chegada dos Portugueses? E os judeus, qual o seu papel neste contexto? Finalmente, qual a política seguida pelos Portugueses no Malabar, por um lado, e pelas autoridades locais, por outro? Por outras palavras, os Portugueses foram bem acolhidos pelos soberanos indianos ou estes privilegiaram os interesses da população local? E qual a resposta portuguesa a esta política? Muitas respostas a estas questões, podemos encontrá-las nos relatos de Zinadím e Rodrigues da Silveira, ambos testemunhas oculares dos acontecimentos que evocam.

\section{Synopsis}

Several questions arise about the arrival of Vasco da Gama in India, in 1492: the intention of the Portuguese were they really commercial? How react the local communities, Hindus, Jews and Muslins, to the unexpected arrival of the Europeans? Is this arrival responsable for a strength imbalance between these groups? In wich camp? Religious, politic, economic or all of them? And the Jews, what was their rule in this context? Finally, how can we define the portuguese politics in Malabar, on one way, and the local one, on the other? In other words, did the Portuguese receive a good reception from the indian sovereigns or not? And what was the portuguese answer to this politics? We can find several answers to these questions in the works of Zinadím and Rodrigues da Silveira, both of them eyewitnesses of he events they relate. 